\title{
Retrospective Multicenter Study on Risk Factors for Surgical Site Infections after Appendectomy for Acute Appendicitis
}

\author{
Louis J.X. Giesen ${ }^{\mathrm{a}}$ Anne Loes van den Boom ${ }^{\mathrm{a}}$ Charles C. van Rossem ${ }^{\mathrm{c}}$ \\ P.T. den Hoed ${ }^{\text {b }}$ Bas P.L. Wijnhoven ${ }^{\mathrm{a}}$ \\ ${ }^{a}$ Department of Surgery, Erasmus Medical Centre, and ${ }^{b}$ Department of Surgery, Ikazia Hospital, Rotterdam, and \\ 'Department of Surgery, Tergooi Hospital, Hilversum, The Netherlands
}

\section{Key Words}

Abdominal infections · Complications · Prognostic factor

\begin{abstract}
Background: Surgical site infections (SSI) are seen in up to $5 \%$ of patients after appendectomy for acute appendicitis. SSI are associated with prolonged hospital stay and increased costs. The aim of this multicenter study was to identify factors associated with SSI after appendectomy for acute appendicitis. Methods: Patients who underwent appendectomy for acute appendicitis between June 2014 and January 2015 in 6 teaching hospitals in the southwest of the Netherlands were included. Patient, diagnostic, intra-operative and disease-related factors were collected from the patients' charts. Primary outcome was surgical site infection. Multivariable logistic regression was performed to identify independent risk factors for SSI. Results: Some 637 patients were included. Forty-two patients developed a SSI. In univariable analysis body temperature $>38^{\circ} \mathrm{C}, \mathrm{CRP}>65$ and complex appendicitis were associated with SSI. After multivariable logistic regression with stepwise backwards elimination, complex appendicitis was significantly associated with SSI (OR 4.09; 95\% Cl 2.04-8.20). Appendiceal stump closure with a stapler device was inversely correlated with SSI (OR 0.40; 95\% Cl 0.24-0.97) Conclusions: Complex appendi-
\end{abstract}

\section{KARGER}

E-Mail karger@karger.com www.karger.com/dsu

\section{(C) 2016 The Author(s) \\ Published by S. Karger AG, Basel 0253-4886/16/0342-0103\$39.50/0}

This article is licensed under the Creative Commons AttributionNonCommercial-NoDerivatives 4.0 International License (CC BYNC-ND) (http://www.karger.com/Services/OpenAccessLicense). Usage and distribution for commercial purposes as well as any distribution of modified material requires written permission. citis is a risk factor for SSI and warrants close monitoring postoperatively. The use of a stapler device for appendiceal stump closure is associated with a reduced risk of SSI.

(c) 2016 The Author(s)

Published by S. Karger AG, Basel

\section{Introduction}

Appendicitis is a common intra-abdominal inflammatory condition. Annually, some 16,000 patients undergo appendectomy in the Netherlands [1]. Acute appendicitis can be divided into 2 subgroups: simple or complex appendicitis. A complex appendicitis is often defined as a gangrenous appendicitis, perforated appendix with or without phlegmon or abscess $[2,3]$. Current guidelines recommend appendectomy for acute appendicitis, although antibiotics as a first-line treatment for a simple appendicitis may be effective in a majority subset of patients [4].

Although acute appendicitis has a very low mortality rate, surgical site infections (SSI), including superficial SSI (SSSI) and organ space infections (OSI), are the most common complications with an incidence of 2.5-5.4 and 1.3-3.0\%, respectively [5-9]. These complications may require re-interventions and are associated with a prolonged hospital stay and increased costs [10]. 
Several studies have investigated factors that are associated with SSI in acute appendicitis including preoperative C-reactive protein (CRP) level, timing of appendectomy, technique of appendiceal stump closure, operative approach (laparoscopic versus open), duration of the operation, complex versus simple appendicitis, body temperature, American Society of Anesthesiology (ASA)classification, age, body mass index (BMI) and gender [9, 11-16]. Most studies however are single center and have strict inclusion and exclusion criteria.

The aim of this study was to identify risk factors for SSI in a large consecutive cohort of patients, including adults and children, who underwent appendectomy in the Southwest of the Netherlands.

\section{Methods}

Patients who underwent appendectomy from June 2014 through January 2015 in 6 teaching hospitals in the Southwest of the Netherlands ( 1 academic center, 5 teaching hospitals) were selected from the hospital administration databases. Inclusion criteria were patients who had appendectomy for an acute appendicitis including simple and complex appendicitis. Exclusion criteria were patients who underwent appendectomy à froid (appendectomy after resolution of the acute inflammation) or appendectomy for another reason (e.g. chronic appendicitis or carcinoma).

Ultrasonography and/or CT was used in most patients as a diagnostic modality for patients with clinical signs of appendicitis according to the Dutch guidelines [1]. All patients were given antibiotic prophylaxis before surgery according to the local hospital guidelines with the vast majority of patients receiving Cefazolin $\left(\right.$ Kefzol $^{\circledR}$ ) 1 gram and Metronidazol (Flagyl ${ }^{\circledR}$ ) 1,500 mg intravenously within $30 \mathrm{~min}$ before skin incision. Operative approach depended on the preference of the attending surgeon. Open appendectomy was performed through an oblique incision in the right lower quadrant of the abdomen (Gridiron's or McBurney's incision). Most patients with a complex appendicitis were given postoperative antibiotics according to the guidelines [1]. In this study, complex appendicitis was defined as gangrenous or perforated appendicitis and/or the presence of purulent peritonitis based on the operation notes. The duration of the use of antibiotics varied among the institutions. Often, a regimen of intravenous broadspectrum antibiotics for 3 or 5 days was defined by the local guidelines on the treatment of secondary peritonitis and to reduce postoperative complications.

Data were extracted from patient charts, operative reports and pathology reports and entered in a database. Preoperative and intraoperative data included gender, patient age, white blood cell count (WBC) and CRP at time of admission, ASA-classification, duration of symptoms, body temperature, time from admission to operation, estimated time between onset of symptoms and operation, duration of the operation, operative approach (laparoscopic or open appendectomy), technique of appendiceal stump closure, severity of appendicitis (complex or simple) and in case of a complex appendicitis the duration of postoperative antibiotics. For the purpose of the study, laparoscopic operations that had to be converted to open were classified as open appendectomy. The study population was divided into 2 groups based on the development of an SSI within 30 days of the operation. SSI was defined according to the CDC definitions [17]. These included OSI and SSSI.

\section{Statistical Analysis}

Continuous data were tested for normality using the ShapiroWilk test. Normally, distributed data were analyzed using independent $t$ test and presented as mean numbers and SD. For nonnormal data, the Mann-Whitney U test was used. Numbers were presented using the median and interquartile range (IQR). Chisquare test or Fisher's exact test were performed on categorical data.

Continuous data were dichotomized using clinically relevant cut-off points or based on previous publications $[11,12,14]$. After univariable analysis, factors with a p value of $<0.30$ were selected for multivariable analysis and entered in a logistic regression model. Using stepwise backward elimination, the best model was selected. At each step, the factor with the highest $p$ value was removed until all factors had a p value smaller than $<0.20$. The Hosmer-Lemeshow test was reported for the model. All statistical analysis was performed using SPSS ${ }^{\circledR}$ version 23.0 (IBM, Armonk, N.Y., USA).

\section{Results}

A total number of 637 patients were included. Patient characteristics are shown in table 1 . Male patients represented $54.3 \%$ of the study group. The median (IQR) age was 31 (18-46) years. Laparoscopic appendectomy was performed in $78.9 \%(n=502)$ of the patients. Ten operations that commenced laparoscopically were converted to an open procedure (2\%). In 8 cases, the laparoscopic procedure could not be continued because of unclear anatomy. In 2 cases, an appendicular infiltrate made it impossible to safely continue with the laparoscopy. Thirty five percent $(n=225)$ of the patients had complex appendicitis of which 110 patients had a perforated appendix.

Some $6.6 \%(n=42)$ of the patients developed an SSI. OSI was seen in 29 patients (4.6\%) and SSSI in 14 patients (2.2\%). Patients with an SSI had a significantly higher median CRP level at the time of admission compared to patients with no SSI (60 vs. $30 \mathrm{mg} / \mathrm{l}, \mathrm{p}=0.004)$. Also, the mean body temperature at time of admission was higher ( 37.9 vs. $\left.37.3^{\circ} \mathrm{C}, \mathrm{p}<0.001\right)$. The length of the operation and time between hospital admission and surgery were not significantly different. The mean time between onset of symptoms and surgery in days was 2.2 and 1.8 days, respectively for patients with SSI versus no SSI $(\mathrm{p}=0.051)$. The prevalence of complex appendicitis was significantly higher in the SSI group (66.7 vs. $33.1 \%, \mathrm{p}<0.001)$. Eighty five percent $(n=192)$ of the patients with complex ap- 
Table 1. Patient characteristics according to SSI

\begin{tabular}{|c|c|c|c|c|}
\hline Gender, male, n (\%) & $346(54.3)$ & $323(54.3)$ & $23(54.8)$ & 0.952 \\
\hline Age, years, median (IQR) & $31(18-46)$ & $30(13-51)$ & $31(18-46)$ & 0.867 \\
\hline \multicolumn{5}{|l|}{ ASA, n (\%) } \\
\hline I & $463(72.9)$ & $27(64.3)$ & $436(73.5)$ & 0.206 \\
\hline II & $150(23.6)$ & $15(35.7)$ & $135(22.8)$ & 0.055 \\
\hline III & $22(3.5)$ & 0 & $22(3.7)$ & $0.388^{*}$ \\
\hline Body temperature at presentation, mean $\pm \mathrm{SD}$ & $37.4 \pm 0.8$ & $37.9 \pm 1$ & $37.3 \pm 0.8$ & $<0.001$ \\
\hline Fever temperature $>38^{\circ} \mathrm{C}, \mathrm{n}(\%)$ & $134(21.5)$ & $17(40.5)$ & $125(20.1)$ & 0.002 \\
\hline WBC count, $10^{9} / 1$, mean $\pm \mathrm{SD}^{*}$ & $14.4 \pm 5$ & $16.5 \pm 5.8$ & $14.2 \pm 4.9$ & 0.004 \\
\hline WBC count $>16,000, \mathrm{n}(\%)$ & $210(33)$ & $19(45.2)$ & $191(32.1)$ & 0.080 \\
\hline CRP, mg/l, median (IQR) & $31(11-72)$ & $60(23-114)$ & $30(11-70)$ & 0.004 \\
\hline $\mathrm{CRP}>65, \mathrm{n}(\%)$ & $181(28.4)$ & $19(45.2)$ & $162(27.2)$ & 0.012 \\
\hline Complex appendicitis, $\mathrm{n}(\%)$ & $225(35.3)$ & $28(66.7)$ & $197(33.1)$ & $<0.001$ \\
\hline Perforated, n (\%) & $110(17.3)$ & $20(47.6)$ & $90(15.1)$ & $<0.001$ \\
\hline Gangrenous, $\mathrm{n}(\%)$ & $72(11.3)$ & $6(14.3)$ & $66(11.1)$ & $0.528^{*}$ \\
\hline Purulent peritonitis, $\mathrm{n}(\%)$ & $148(23.2)$ & $21(50)$ & $127(21.3)$ & $<0.001$ \\
\hline Stump closure with stapler device, n (\%) & $268(42.1)$ & $13(31)$ & $255(42.9)$ & 0.131 \\
\hline Total operation time, min, median (IQR) & $39(31-51)$ & $43(33-56)$ & $39(31-51)$ & 0.309 \\
\hline Length of operation $>60 \mathrm{~min}, \mathrm{n}(\%)$ & $76(11.9)$ & $68(11.4)$ & $8(19)$ & 0.141 \\
\hline Complex appendicitis on final pathology & $120(18.8)$ & $19(45.2)$ & $101(17)$ & $<0.001$ \\
\hline Length of stay, days, median (IQR) & $2(2-4)$ & $4(3-7)$ & $2(2-4)$ & $<0.001$ \\
\hline
\end{tabular}

* Fisher's exact test.

Table 2. Logistic regression analysis results

\begin{tabular}{|c|c|c|c|c|}
\hline & $\begin{array}{l}\text { Univariable analysis, } \\
\text { OR (95\% CI) }\end{array}$ & $\mathrm{p}$ value & $\begin{array}{l}\text { Multivariable analysis, } \\
\text { OR (95\% CI)* }\end{array}$ & $\mathrm{p}$ value \\
\hline $\mathrm{CRP}>65$ & $2.28(1.21-4.30)$ & 0.011 & - & \\
\hline $\mathrm{WBC}>16,000 / \mu \mathrm{l}$ & $1.75(0.93-3.30)$ & 0.083 & - & \\
\hline Complex appendicitis & $4.04(2.08-7.85)$ & $<0.001$ & $4.09(2.04-8.20)$ & $<0.001$ \\
\hline Fever (temperature $>38^{\circ} \mathrm{C}$ ) & $2.70(1.41-5.16)$ & 0.003 & $1.94(0.99-3.80)$ & 0.054 \\
\hline Stapler device (vs. endoloops) & $0.60(0.31-1.17)$ & 0.085 & $0.40(0.24-0.97)$ & 0.040 \\
\hline Total operation time $>60 \mathrm{~min}$ & $1.82(0.81-4.10)$ & 0.146 & - & \\
\hline Time to operating room $>6 \mathrm{~h}$ & $0.90(0.48-1.69)$ & 0.747 & - & \\
\hline Laparoscopic vs. open & $0.74(0.36-1.52)$ & 0.414 & - & \\
\hline ASA II + III vs. ASA I & $1.55(0.80-2.99)$ & 0.191 & - & \\
\hline
\end{tabular}

* Hosmer-Lemeshow goodness of fit $(\mathrm{p}=0.763)$.

pendicitis received postoperative antibiotics. The median (IQR) duration was 5 (3-5) days. In subgroup analysis, no difference was seen in the number of SSI between patients receiving a 3 or 5-day antibiotic regimen ( 7 of 43 vs. 14 of $82, \mathrm{p}=0.796)$. Nine factors were selected and entered in a multivariable logistic regression model (table 2). Complex appendicitis (OR 4.09; 95\% CI 2.04-8.20) was independently associated with the development of SSI. The use of a stapler device was inversely related to SSI (OR 0.40 ; 95\% CI 0.24-0.97). 


\section{Discussion}

This study shows that SSI occur in $6.6 \%$ of patients after appendectomy for appendicitis. A complex appendicitis is the main risk factor for the development of SSI (OR 4.09; 95\% CI 2.04-8.20). This finding is supported by the literature. Kelly et al. [13] demonstrated that complex appendicitis is a risk factor for SSI in children undergoing appendectomy (OR 4.85; 95\% CI 3.06-7.71) [13, 16]. Other studies also show higher rates of SSI in complex appendicitis compared to simple appendicitis $[5,12]$. The overall rate of SSI $(6.6 \%)$ in this study is consistent with the literature. The rate of OSI in this study, however, is $4.6 \%$, which is higher than that reported by others (1.6$3.1 \%)[5,8,9]$. The relative high number of patients with complex appendicitis in our study could explain this. Some 225 patients (35.3\%) had a complex appendicitis. Other studies report slightly lower rates $(23-30 \%)[5,8$, $18]$.

The intraoperative diagnosis served as the reference for the diagnosis of complex appendicitis. It can be questioned if the final pathology report is more objective than the intraoperative diagnosis. Only half $(53.5 \%)$ of the gangrenous or perforated appendices were confirmed by pathology. A recent paper by Farach et al. [19] shows that the correlation between clinical and pathological assessment is low and operative findings are a better predictor of the clinical course.

An interesting finding is the reduced risk of SSI when a stapler device is used for appendiceal stump closure (OR 0.47; 95\% CI 0.23-0.96). A large study by Beldi et al. [15] also showed lower rates of SSI in patients with non-perforated appendicitis. The cost of a stapler device is much higher than the cost of 2- or 3 endoloops. Nonetheless, a reduction in SSI when using a stapler device may be more cost effective than the use of endoloops when taking total hospital costs (readmission, re-interventions) into account. However, clips were not used for stump closure in this study. A recent meta-analysis shows clips might be more cost-effective than endoloops [20]. Future prospective cost-effectiveness studies are needed to get more insight, but these studies likely need a large number of patients given the low rate of infectious complications after appendectomy.

Interestingly, there were also some factors not associated with SSI despite earlier reports demonstrating an increased risk for SSI. Time from admission to operation of more than $6 \mathrm{~h}$ was not associated with the development of SSI in contrast to a large study by Teixeira et al. [11]. In that study, however, no information regarding the duration of symptoms is reported. The time between onset of symptoms and appendectomy might be more relevant than the time from admission to surgery. We combined the duration of symptoms with the time from admission to operation, but no significant difference could be found between the 2 groups ( 2.2 vs. 1.8 days, $p=$ 0.051 ).

Higher preoperative levels of CRP and WBC counts were present in the SSI group. These variables were removed from the multivariable model since no relation with SSI was demonstrated. An explanation could be that patients with complex appendicitis have higher inflammatory parameters as a result of peritonitis and there is an interaction between these 2 factors [21]. Shimizu et al. [14] showed that CRP levels higher than 65 is a risk factor for the development of an SSI. A closer look at this study reveals a much higher rate of SSI (16.3\%). It should also be noted that the multivariable logistic regression model included 14 variables, while only 49 events occurred; this could lead to serious overfitting.

Limitations of our study should be mentioned as well. The data were collected retrospectively and as a result, not all variables of interest could be retrieved. It would have been interesting to know the prevalence of diabetes mellitus and the patients' BMI. On the other hand, among the variables we collected, there were no missing values. Part of the study period included a nationwide survey (snapshot study) on appendicitis and data were recorded prospectively [22]. Second, the number of patients included limits the number of factors for multivariable analysis and overfitting may have occurred (type I error). A type II error may also be present, given the lack of association between several factors and SSI as reported before in larger studies. The multicenter approach and study population however, contribute to the generalizability of the results. This cohort is a reflection of the population who undergo appendectomy for acute appendicitis in the Netherlands including patients seen in small, large and academic hospitals.

Unfortunately, it is difficult to influence the outcome after complex appendicitis and reduce the incidence of SSI. There is increased awareness of a preoperative complex appendicitis by a risk score as recently published, which may direct the operating team to adhere more strictly to perioperative interventions to reduce the rate of SSI [20]. Peritoneal lavage has not been proven effective $[23,24]$. Preoperative antibiotic prophylaxis reduces the number of SSI but is already widely integrated [2, 25]. Perhaps more attention can be given to the timing of the administration of antibiotic prophylaxis $[26,27]$. 
It is recommended by the guidelines that antibiotic should be continued postoperatively in patients with complex appendicitis; however, increasing evidence suggests that the benefit of systemic antimicrobial therapy is limited after adequate source control including appendectomy $[8,22,28]$. The use of a stapler device might reduce the incidence of SSI. However, a prospective study has to be performed to make recommendations regarding the most cost-effective and safest stump closure technique.

\section{References}

1 Bakker OJ, Go PM, Puylaert JB, Kazemier G, Heij HA; Werkgroep Richtlijn Diagnostiek en Behandeling van Acute Appendicitis: [Guideline on diagnosis and treatment of acute appendicitis: imaging prior to appendectomy is recommended]. Ned Tijdschr Geneeskd 2010;154:A303.

2 Andersen BR, Kallehave FL, Andersen HK: Antibiotics versus placebo for prevention of postoperative infection after appendicectomy. Cochrane Database Syst Rev 2005;20: CD001439.

3 Simillis C, Symeonides P, Shorthouse AJ, Tekkis PP: A meta-analysis comparing conservative treatment versus acute appendectomy for complicated appendicitis (abscess or phlegmon). Surgery 2010;147:818-829.

4 Varadhan KK, Neal KR, Lobo DN: Safety and efficacy of antibiotics compared with appendicectomy for treatment of uncomplicated acute appendicitis: meta-analysis of randomised controlled trials. BMJ 2012;344:e2156.

5 Cueto J, D’Allemagne B, Vázquez-Frias JA, Gomez S, Delgado F, Trullenque L, et al: Morbidity of laparoscopic surgery for complicated appendicitis: an international study. Surg Endosc 2006;20:717-220.

6 Sauerland S, Jaschinski T, Neugebauer EA: Laparoscopic versus open surgery for suspected appendicitis. Cochrane Database Syst Rev 2010;10:CD001546.

7 Bennett J, Boddy A, Rhodes M: Choice of approach for appendicectomy: a meta-analysis of open versus laparoscopic appendicectomy. Surg Laparosc Endosc Percutan Tech 2007; 17:245-255.

8 van Rossem CC, Schreinemacher MH, Treskes $\mathrm{K}$, van Hogezand RM, van Geloven AA: Duration of antibiotic treatment after appendicectomy for acute complicated appendicitis. Br J Surg 2014;101:715-719.

9 Fleming FJ, Kim MJ, Messing S, Gunzler D, Salloum R, Monson JR: Balancing the risk of postoperative surgical infections: a multivariate analysis of factors associated with laparoscopic appendectomy from the NSQIP database. Ann Surg 2010;252:895-900.
10 Mangram AJ, Horan TC, Pearson ML, Silver LC, Jarvis WR: Guideline for prevention of surgical site infection, 1999. Centers for disease control and prevention (CDC) hospital infection control practices advisory committee. Am J Infect Control 1999;27:97-132; quiz 133-134; discussion 96.

11 Teixeira PG, Sivrikoz E, Inaba K, Talving P, Lam L, Demetriades D: Appendectomy timing: waiting until the next morning increases the risk of surgical site infections. Ann Surg 2012;256:538-543.

12 Margenthaler JA, Longo WE, Virgo KS, Johnson FE, Oprian CA, Henderson WG, et al: Risk factors for adverse outcomes after the surgical treatment of appendicitis in adults. Ann Surg 2003;238:59-66.

13 Kelly KN, Fleming FJ, Aquina CT, Probst CP, Noyes K, Pegoli W, et al: Disease severity, not operative approach, drives organ space infection after pediatric appendectomy. Ann Surg 2014;260:466-471; discussion 472-473.

14 Shimizu T, Ishizuka M, Kubota K: The preoperative serum C-reactive protein level is a useful predictor of surgical site infections in patients undergoing appendectomy. Surg Today 2014;45:1404-1410.

15 Beldi G, Vorburger SA, Bruegger LE, Kocher $\mathrm{T}$, Inderbitzin D, Candinas D: Analysis of stapling versus endoloops in appendiceal stump closure. Br J Surg 2006;93:1390-1393.

16 van den Boom AL, Gorter RR, van Haard PM, Doornebosch PG, Heij HA, Dawson I: The impact of disease severity, age and surgical approach on the outcome of acute appendicitis in children. Pediatr Surg Int 2015;31:339345.

17 Horan TC, Andrus M, Dudeck MA: CDC/ NHSN surveillance definition of health careassociated infection and criteria for specific types of infections in the acute care setting. Am J Infect Control 2008;36:309-332.

18 Wullstein C, Barkhausen S, Gross E: Results of laparoscopic vs. conventional appendectomy in complicated appendicitis. Dis Colon Rectum 2001;44:1700-1705.

19 Farach SM, Danielson PD, Walford NE, Harmel RP Jr, Chandler NM: Operative findings are a better predictor of resource utilization in pediatric appendicitis. J Pediatr Surg 2015;50:1574-1578.
20 Shaikh FM, Bajwa R, McDonnell CO: Management of appendiceal stump in laparoscopic appendectomy - clips or ligature: a systematic review and meta-analysis. J Laparoendosc Adv Surg Tech A 2015;25:21-27.

21 Gorter RR, van den Boom AL, Heij HA, Kneepkens CM, Hulsker CC, Tenhagen M, et al: A scoring system to predict the severity of appendicitis in children. J Surg Res 2016;200: 452-459.

22 van Rossem CC, Schreinemacher $\mathrm{MH}$, van Geloven AA, Bemelman WA; Snapshot Appendicitis Collaborative Study Group: Antibiotic duration after laparoscopic appendectomy for acute complicated appendicitis. JAMA Surg 2016;151:323-329.

23 Cheng Y, Zhou S, Zhou R, Lu J, Wu S, Xiong $\mathrm{X}$, et al: Abdominal drainage to prevent intraperitoneal abscess after open appendectomy for complicated appendicitis. Cochrane Database Syst Rev 2015;2:CD010168.

24 Schwarz A, Bölke E, Peiper M, Schulte am Esch J, Steinbach G, van Griensven M, et al: Inflammatory peritoneal reaction after perforated appendicitis: continuous peritoneal lavage versus non lavage. Eur J Med Res 2007; 12:200-205.

25 Daskalakis K, Juhlin C, Påhlman L: The use of pre- or postoperative antibiotics in surgery for appendicitis: a systematic review. Scand J Surg 2014;103:14-20.

26 Steinberg JP, Braun BI, Hellinger WC, Kusek L, Bozikis MR, Bush AJ, et al: Timing of antimicrobial prophylaxis and the risk of surgical site infections: results from the trial to reduce antimicrobial prophylaxis errors. Ann Surg 2009;250:10-16.

27 Hawn MT, Richman JS, Vick CC, Deierhoi RJ, Graham LA, Henderson WG, et al: Timing of surgical antibiotic prophylaxis and the risk of surgical site infection. JAMA Surg 2013; 148:649-657.

28 Sawyer RG, Claridge JA, Nathens AB, Rotstein OD, Duane TM, Evans HL, et al: Trial of short-course antimicrobial therapy for intraabdominal infection. N Engl J Med 2015; 372:1996-2005.
Study on Risk Factors for SSI after Appendectomy for Acute Appendicitis 